\title{
Nudge to Promote Sustainable Shopping Lifestyle ${ }^{\dagger}$
}

\author{
Irina Safitri Zen \\ Institute Sultan Iskandar, Faculty of Built Environment \& Surveying, Universiti Teknologi Malaysia, \\ Skudai 81310, Johor State, Malaysia; irinasafitri@utm.my or irinasafitri@gmail.com; Tel.: +60-7-558-4286 \\ + Presented at the Economy, Sustainable Development and Energy International Conference (ESDEIC), \\ Queen Margaret University, in Edinburgh (Scotland, UK), 25-27 June 2018.
}

Published: 28 October 2018

\begin{abstract}
The complexity of consumer's changes towards green behavior, such as sustainable shopping lifestyle is a challenge for the government and its public policy. Most of the traditional regulatory approach, such as plastic bag ban or tax was hoping for immediate result of the consumer behavioral changes. Thus, changes the consumer behavior towards green practices becomes the central issues where its implication is in a significant reduction of plastic bag consumption as well as its detrimental effect on the environment. Aims to analyze the No Plastic Bag Campaign in Malaysia, the concern is to what extent it has the potential to change the consumer behavior in a subtle way or nudge. The paper evaluates the in-situ approaches of the current campaign in a designed context of choices architect, libertarian paternalism and the supermarket corporate social responsibility, CSR. More influential informational campaign material for reusable bags was suggested at the check-out counter. The Zero Waste initiative is needed to reduce dependency to plastic bag as a disposal method. Finally, the comprehensive approach in the establishment of a new social norm to nudge sustainable shopping lifestyle was suggested than a single approach of banning the plastic bag.
\end{abstract}

Keywords: consumers; behavior; nudge; plastic bag; social norm; sustainable lifestyle

\section{Introduction}

Most of the traditional approach of top-down plastic tax or levy was conducted with a hope of consumer behavior changes accordingly. This type of tax is different from the original concept of plastic tax where the polluter pays the externalities or side effects of consuming plastic bag to the environment [1]. However, it was succeeded in changing the consumer behavior and decreasing among of plastic bag use in Ireland [2], but it did not happen in Botswana after a certain period of time [3]. Some governments are reluctant to regulate the plastic bag tax due to the fear of public criticism and loss of political support [4]. One of the subtle ways to support the anti-plastic bag ban is by installing new shopping habits by establishing a new norm using social influence and social norms [5]. Hence, nudge play a crucial role. Malaysia's No Plastic Bag Campaign was used as a design context of this study, we further analyze whether it is possible to nudge a sustainable shopping lifestyle. Despite banning plastic bag is an intrusive approach, the establishment of a new habit which is back to the 'old fashion' bring your own shopping bag requires a long-term effort to reinstall the old habits in the current modern shopping' context. It is until it becomes a new norm in the society [5].

Little is known about the approaches of the No Plastic Bag Campaign and the plastic charges from the behavioral economics perspective. The economic instrument such as plastic bag tax was claimed as a successful approach to reducing plastic bag usage [2,3]. Understanding what is going on at consumer's level vis-à-vis the stakeholder involves is the key to understand under which conditions nudge can be one of the effective approaches for consumer's behavior towards sustainable shopping lifestyle. By using Malaysia's No Plastic Bag Campaign as a case study, this paper will 
discuss to what extent the nudge concept has the potential to support the sustainable shopping lifestyle in a specific design context.

\section{Literature Review}

Behavioral change has been the biggest challenge for the government in almost every aspect of public policy. Most of the approach, such as prohibit the use of cigarette or high sugar contents of drink for healthy purposes or ban the use of the plastic bag, are implemented to discourage the consumption concerning the effect that reduces the welfare of others or libertarian paternalism [6]. It is strengthened by regulatory measures such as ban, tax, prohibition as a mandatory or regulatory approach. However, some governments including Malaysia are reluctant to proceed with such an approach due to skepticism towards regulatory approach [7]. Hence, the continuous educational campaign and awareness were conducted to establish a new norm in society. It's a societal learning process for the stakeholder involves in this initiative. Up to this level, the tax imposed is not for internalizing the externalities of consuming plastic bag as the original concept of environmental taxation [1].

Initially, the plastic bag charges and the No Plastic Bag campaign are managed and conducted by the supermarket as a partner of government, the Ministry of Domestic Affairs, Cooperative and Consumerism [7]. It is not a plastic bag tax since there was no regulation involved. Furthermore, it becomes sub-national or State matters since the various state in Malaysia organized independently with their collaborative effort with the supermarket's corporate social responsibility, CSR. Among the earlier initiator is the Penang State government, followed by Selangor State and it becomes Nationwide concerns where formal binding signed between the Ministry of Domestic Affairs, Cooperative and Consumerism and its supermarket chain partner. Moreover, since the State is under the Ministry of Urban Wellbeing, Housing and Local Government, the initiatives become the ministry major concern under the New Malaysia elected government in 2018. Nevertheless, the Ministry of Energy, Science, Technology and Climate Change prepared Malaysia's roadmap towards zero singleuse plastics 2018-2030.

\subsection{Nudge the Sustainable Shopping Lifestyle and Other Related Issues}

From the overall complexities of anti-plastic bag usage, educational campaign and plastic bag charges, further, the creation of design context involves supermarket are considered as the architect of choice. It is to reinstall the old habits prior to plastic bag usage to establish a sustainable shopping lifestyle. Through time, as the new norm of sustainable shopping lifestyle established where people bring their own shopping bag and avoid the use of plastic bags that are more likely to encourage other consumers to perform and will be maintaining a self-image as a morally responsible person [5]. More young generation carry their own shopping bags than single-use of plastic bag in China [8]. Thaler and Sunstein stated Nudge as: “... because our choices are always influenced by the decision-making context, and because such influence is often manipulated by far more intrusive or subtle measures-taxation, regulation, marketing, etc. - nudging is an admissible approach to behavior change in public policymaking" [9]. The anti-plastic bag is implemented at the checkout counter of the supermarket in Malaysia.

Prior to plastic bag ban, there is overconsumption on a single use of plastic bag. Despite the continuous of campaign efforts to refuse the single use of plastic bag and improve the consumer awareness, the gap between green knowledge and actual practice remain the same $[5,7,10]$. Hence the effort is needed to influence the consumer's behavioral changes in a subtle way. Charging 20 cents MYR for each plastic bag and offered the reusable bags are the effort to limits the single use of plastic bag. It was designed as a choice of architects to influence behavioral changes in a subtle way [8]. This process is called a nudging process.

Furthermore, supermarket also provides choices to nudge a sustainable shopping lifestyle. It is where the charging of plastic bag cause creates default options for consumers to switch their habits into sustainable shopping lifestyle. As Thaler and Sunstein summation on nudge which quite simply: "because our choices are always influenced by the decision-making context, and because such influence is often manipulated by far more intrusive or subtle measures-taxation, regulation, marketing, etc.-nudging is an 
admissible approach to behavior change in public policymaking". It needs a various reinforcing mechanism to analyze to what extent the consumers practices the new sustainable shopping lifestyle after charging plastic bag took place. Understand what is going on at consumer's level is the key to understand why and under which conditions this anti-plastic bag policy can be effective, and how to improve the program in the future to nudges effectively the consumer's behavior towards sustainable shopping lifestyle.

Other crucial reasons for secondary users of the single use of plastic bag is related to disposable waste behavior. It is common for a household in Malaysia uses the plastic bag mainly for garbage bag (45\%) [7]. It is followed by 'carrying goods' 32\%, 'thrown with other disposal' $14 \%$ and only a small percentage reuse it for shopping, 9\%. This shows the high dependency of household with a single use of plastic bag. In other words, failure to tackling this issue may not cure the core problem of the use of the plastic bag. This situation closely related with household practice waste separation where putting recyclable items in a special curbside of multiple uses recycle bin in a special recycle collection [10] may reduce the amount of waste tight into a plastic bag and goes to landfill. Nevertheless, the intensive organic composting waste at the neighborhood level also helps in reduce their dependency with a plastic bag or called as Zero Waste initiative. All of this effort completes the full cycle of the circular economic for a plastic bag.

\subsection{The Government's Extended Hand}

The involvement of supermarket CSR in No Plastic Bag campaign in Malaysia is an example of how government plays their role in actively creating and manage new norms $[7,11]$ which is less coercive and less expensive than other regulatory measures [8]. This is also part of the supermarket organizational societal learning for a new form of CSR [11]. The approach where the government does not restrict people freedom of choice through regulation, it was highlighted by Thaler and Sunstein (2008), as an alteration in the architecture of decision making such as product placement, opt-in and opt-out schemes to move people in great numbers toward better behaviors. The same fact found in China since 2008 where not providing customers with plastic bags at checkouts obliges them to ask for or even pay for them and in Italy since January 1st, 2011. Hence, the study identified the two primary crucial approaches of supermarket CSR in altering choice architecture that could have a significant impact on social norms in this plastic bag issues is included by making behaviors more convenient in use reusable bag. Second, by making them more visible by establishing a green shopping lifestyle as a new state of the art. Hence, the useful informational material campaign may function as crucial tools to educate that their effort is worthwhile to save the environment and for the future generation by avoiding the declining of the welfare of others.

The similar approach where government works closely with other parties to reduce dependency with a plastic bag is in City of San Diego. The approval for the adoption and implementation of plastic ordinance is to restricting the use of plastic and paper single-use carryout bags, and promoting the use of reusable bags [12].

\section{Conclusions}

The study revealed Malaysia No Plastic Bag Campaign adopt nudge for sustainable shopping lifestyle to a certain degree as to support the existing economic instrument of plastic bag charges and suasive educational campaign. It was established a more heuristic approach to reinstall new social norm promoting reusable bag instead of depending on a single approach of banning the plastic bag usage. (i) The study suggested for more continuous strategic and educational campaign reusable bags such as putting the green informational impact of using reusable bags could save more trees compared to single-use a plastic bag, (ii) Display reusable shopping bag close to the check-out counter to nudge opt for more environmentally friendly than a single-use plastic bag, (iii) gives more incentives for green shoppers who maintain they're social morally status. In the situation where tax becomes less considerate, collaborate with a supermarket as part of their CSR activities and its crucial function act as a choice architect to nudge a sustainable shopping lifestyle is advisable. The study recognized that of what the behavioral economist Richard Thaler and legal scholar Cass R. Sunstein 
have suggested 'the very cognitive boundaries, biases, and habits that cause these mistakes may be systematically utilized by private and public institutions to modify individual-level behaviors in people's own declared self-interests'.

Authors Contributions: I.S.Z. conceived and designed the experiments and analyzed the data, literature review and the discussion.

Funding: The study was funded by the Ministry of Education of Malaysia (Vot No. 00M88) and part of the Research University Grant of Universiti Teknologi Malaysia (GUP-UTM) (Vot 08J98) with a research project title 'No Plastic Bag Campaign in Malaysia: the legislative measures, consumer behavior and willingness to pay (WTP) of plastic bag levy'.

Conflicts of Interest: The authors declare no conflict of interest. The founding sponsors had no role in the design of the study; in the collection, analyses, or interpretation of data; in the writing of the manuscript, and in the decision to publish the results.

\section{References}

1. Pearce, D.; Turner, R.K. Packaging waste and the polluter pays principle: A taxation solution. J. Environ. Plan. Manag. 1992, 35, 5-15.

2. Convery, F.; McDonnell, S.; Ferreira, S. The most popular tax in Europe? Lessons from the Irish plastic bags levy. Environ. Resour. Econ. 2007, 18, 1-11.

3. Dikgang, J.; Leiman, A.; Visser, M. Analysis of the plastic-bag levy in South Africa. Resour. Conserv. Recycl. 2012, 66, 59-65.

4. Ritch, E.; Brennan, C.; MacLeod, C. Plastic bag politics: Modifying consumer behaviour for sustainable development. Int. J. Consum. Stud. 2009, 33, 168-174.

5. Elgaaied-Gambier, L.; Monnot, E.; Reniou, F. Using descriptive norm appeals effectively to promote green behavior. J. Bus. Res. 2018, 82, 179-191.

6. Hansen, P.G.; Skov, L.R.; Skov, K.L. Making Healthy Choices Easier: Regulation versus Nudging. Annu. Rev. Public Health 2016, 37, 237-251.

7. Zen, I.S.; Ahamad, R.; Omar, W. No plastic bag campaign day in Malaysia and the policy implication. Environ. Dev. Sustain. 2013, 15, 1259-1269.

8. Watts J. China plastic bag ban has saved $1.6 \mathrm{~m}$ tonnes of oil. The Guardian, 22 May 2008.

9. Thaler, R.; Sunstein, C. Nudge-Improving Decisions about Health, Wealth and Happiness; Yale University Press: New Haven, CT, USA, 2008.

10. Zen, I.S.; Siwar, C. An Analysis of Household Acceptance of Curbside Recycling Scheme in Kuala Lumpur, Malaysia. Habitat Int. 2015, 47, 248-255.

11. Richards, C.; Zen, I.S. From Surface to Deep Corporate Social Responsibility: The Malaysian No Plastic Bags Campaign as both Social and Organizational Learning. J. Glob. Responsib. 2016, 7, 275-287.

12. The City fo San Diego. Final Environmental Impact Report. Project No. 412659. SCH No. 2015051034. Available online: https://www.sandiego.gov/sites/default/files/1_feir_single-use_carryout_bag_reduction_ ordinance_063016.pdf. (accessed on 25 October 2018).

(C) 2018 by the authors. Licensee MDPI, Basel, Switzerland. This article is an open access article distributed under the terms and conditions of the Creative Commons Attribution (CC BY) license (http://creativecommons.org/licenses/by/4.0/). 